UNIVERSIDADE DE BRASILIA - UNB

FACULDADE DE CIÊNCIAS DA SAÚDE

NÚCLEO DE ESTUDOS EM EDUCAÇÃO E PROMOÇÃO DA SAÚDE - NESPROM CENTRO DE ESTUDOS AVANÇADOS MULTIDISCIPINAR - CEAM

CURSO DE ESPECIALIZAÇÃO EM EDUCAÇÃO E PROMOÇÃO DA SAÚDE

Wanessa Pimenta Rosas

Associação entre infecção por Papilomavírus Humano e câncer de colo uterino

PROFESSORA MSC. CAROLINA CONCEIÇÃO PRADO

BRASILIA, 
UNIVERSIDADE DE BRASILIA - UNB

FACULDADE DE CIÊNCIAS DA SAÚDE

NÚCLEO DE ESTUDOS EM EDUCAÇÃO E PROMOÇÃO DA SAÚDE - NESPROM CENTRO DE ESTUDOS AVANÇADOS MULTIDISCIPINAR - CEAM

CURSO DE ESPECIALIZAÇÃO EM EDUCAÇÃO E PROMOÇÃO DA SAÚDE

Wanessa Pimenta Rosas

\section{Associação entre infecção por Papilomavírus Humano e câncer de colo uterino}

Trabalho de Conclusão de Curso - TCC -
Apresentado para a Banca Examinadora do Curso
de Educação e Promoção da Saúde da
Universidade de Brasília, como exigência parcial
da obtenção do grau de especialista em Educação
e Promoção da Saúde.

Professora: Msc. Carolina C. Prado

BRASILIA, 
A mente que se abre a uma nova idéia jamais volta ao seu tamanho original.

Albert Einstein 


\section{RESUMO}

O Ministério da Saúde afirma que a associação entre papilomavírus humano (HPV) e câncer de colo uterino é aproximadamente 10 a 20 vezes maior do que tabagismo e câncer de pulmão e que surgem anualmente em todo o mundo aproximadamente 500 mil casos novos de câncer cervical, levando ao óbito 230 mil mulheres, aproximadamente. O Instituto Nacional do Câncer estima para o ano de 2010, o surgimento de 18.430 novos casos de câncer cervical no Brasil. Com o objetivo de conhecer melhor a relação entre o papilomavírus humano (HPV) e o desenvolvimento do câncer cervical, desenvolveu-se esta revisão bibliográfica. Para elaboração deste estudo foram pesquisados no portal Scielo Brasil, artigos científicos publicados entre os anos de 1999 e 2009. Desta pesquisa, foram selecionados doze artigos que tratavam da relação entre HPV e carcinoma cervical. Vários autores demonstraram em seus estudos a prevalência de certos tipos de HPV, em especial o HPV-16 e o HPV-18 na etiopatogênese do câncer cervical, sendo que os genótipos de HPV de alto risco foram identificados em 52,4 a 100\% dos casos de lesões neoplásicas e pré neoplásicas. A Organização Mundial de Saúde já reconhece este vírus como agente etiológico responsável pela oncogênese cervical. Embora, mesmo sendo uma patologia passível de prevenção e cura, o câncer cervical continua sendo causa de mortalidade em milhares de mulheres, especialmente nos países subdesenvolvidos. Assim sendo, o diagnóstico precoce, o conhecimento dos fatores de risco e o desenvolvimento de ações de promoção e educação em saúde são passos importantíssimos para interrupção da cadeia de transmissão do HPV e, conseqüentemente, na prevenção do câncer cervical e na redução dos índices de mortalidade por esta patologia em nosso país.

PALAVRAS CHAVES: Papilomavírus humano (HPV), câncer uterino, neoplasia cervical, oncogênese cervical. 


\begin{abstract}
The Health Ministry said that the association between human papillomavirus (HPV) and cervical cancer is about 10 to 20 times greater than smoking and lung cancer and that there are annually around the world about 500 new cases of cervical cancer leading to death 230 thousand women, about. The National Cancer Institute estimates for the year 2010, the emergence of 18. 430 new cases of cervical cancer in Brazil. In order to better understand the relationship between human papillomavirus (HPV) and development of cervical cancer, developed this literature review. To complete this study were determined in the portal Scielo Brazil, scientific articles published between the years 1999 and 2009. This research, we selected twelve articles dealing with the relationship between HPV and cervical carcinoma. Several authors have demonstrated in their studies the prevalence of certain types of HPV, especially HPV-16 and HPV-18 in the etiopathogenesis of cervical cancer, and the genotypes of high risk HPV types were identified in 52.4 to $100 \%$ of cases of neoplasia and preneoplastic. The World Health Organization has recognized this virus as the etiologic agent responsible for cervical oncogenesis. Although, despite being a preventable disease and cure, cervical cancer remains a cause of death in thousands of women, especially in underdeveloped countries. Therefore, early diagnosis, knowledge of risk factors and the development of health promotion and health education are important steps to interrupt the chain of transmission of HPV and, consequently, the prevention of cervical cancer and reducing mortality by this disease in our country.
\end{abstract}

KEY WORDS: human papillomavirus (HPV), uterine cancer, cervical cancer, cervical oncogenesis. 


\section{SUMÁRIO}

RESUMO

ABSTRACT

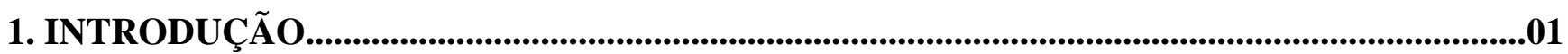

2. OBJETIVOS.............................................................................................................................................03

2.1 Objetivo geral................................................................................................................................03

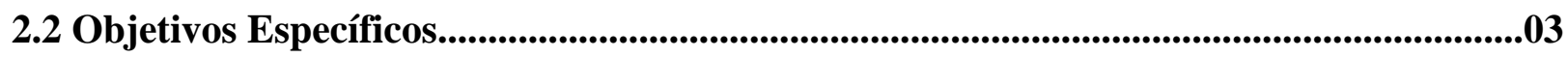

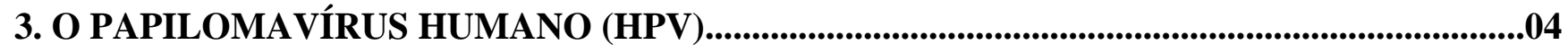

3.1 Infecção pelo papilomavírus humano (HPV)..............................................................04

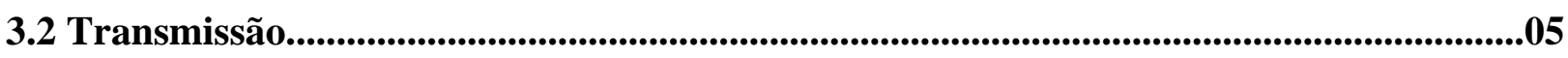

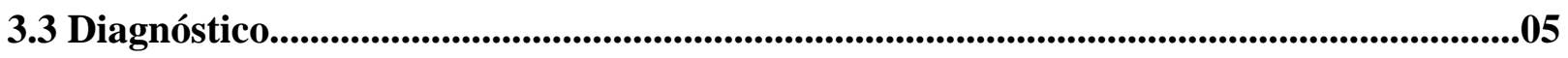

3.4 Tratamento....................................................................................................................................................06

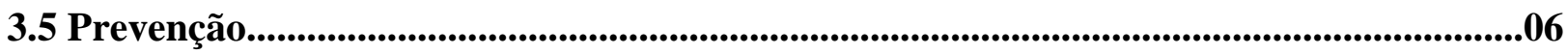

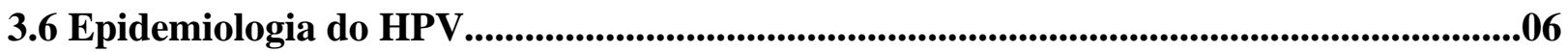

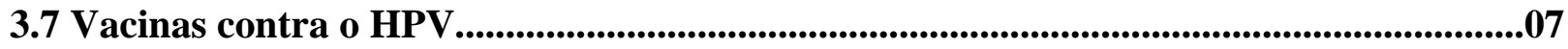

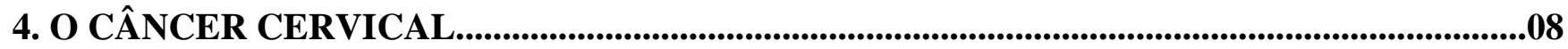

4.1 Manifestações Clínicas......................................................................................................................08

4.2 Epidemiologia do câncer cervical......................................................................................................08

4.3 Co-fatores no surgimento do câncer cervical.........................................................................09

4.4 Tratamento.............................................................................................................................................09

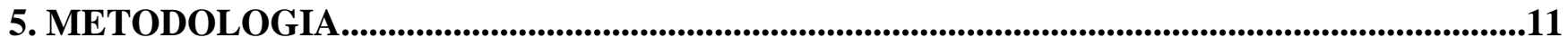

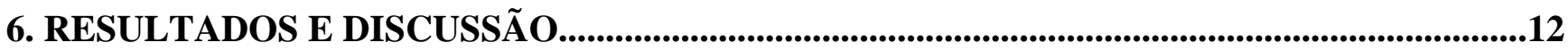

7. CONSIDERAÇÕES FINAIS....................................................................................................................22

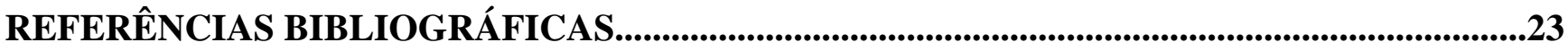




\section{INTRODUÇÃO}

As doenças sexualmente transmissíveis (DST) são hoje um grave problema de saúde pública mundial, sendo consideradas um fator facilitador para a transmissão sexual do vírus HIV. Muitas destas doenças, quando não diagnosticadas precocemente, podem levar a complicações como: esterilidade, cânceres genitais, transmissão de mãe para filho durante a gestação causando aborto ou má formação fetal e até mesmo levando ao óbito.

A Organização Mundial de Saúde estima que exista um total de 340 milhões de casos novos por ano de DST curáveis em todo o mundo. Cerca de 10 milhões de brasileiros já tiveram algum sinal ou sintoma de doenças sexualmente transmissíveis, sendo que 6,6 milhões são homens e 3,7 milhões são mulheres. Dentre os infectados é comum que apenas uma pequena quantidade procure o serviço de saúde para receber o tratamento adequado. Muitos, por constrangimento ou por outros motivos, preferem procurar diretamente o balconista da farmácia ou utilizar de outros métodos alternativos e pouco confiáveis (BRASIL, 2006, p.11).

De acordo com Rosa et. al. (2009) aproximadamente 40 \% das mulheres que tem vida sexual ativa são infectadas pelo papilomavírus humano (HPV). Estudos demonstraram a relação entre alguns tipos de HPV de alto potencial oncogênico com o surgimento do câncer uterino.

O câncer do colo do útero é o segundo tipo de câncer mais freqüente entre as mulheres, com aproximadamente 500 mil casos novos por ano no mundo, sendo responsável pelo óbito de, aproximadamente, 230 mil mulheres por ano. Sua incidência é cerca de duas vezes maior em países menos desenvolvidos quando comparada aos países mais desenvolvidos (BRASIL, 2009, p.33).

A associação entre o papilomavírus humano (HPV) e o câncer de colo uterino é aproximadamente 10 a 20 vezes maior do que o tabagismo e o câncer de pulmão (BRASIL, 2002, p.15).

Em função desta realidade, os profissionais de saúde têm papel importantíssimo na prevenção da infecção pelo HPV e conseqüentemente na prevenção do câncer de colo uterino. Diante da magnitude dos danos causados pelas DST, em especial pelo HPV, é de grande importância realizar o diagnóstico precoce e o manejo adequado dos casos, com objetivo de evitar complicações e mortes. A busca do parceiro também é de extrema importância para interrupção da cadeia de transmissão do HPV. 
Neste ínterim, este estudo visa conhecer a relação entre a presença do papilomavírus humano (HPV) e o câncer de colo uterino, por meio de revisão bibliográfica de artigos científicos que descreveram esta inter-relação. Desta forma, espera-se auxiliar na criação de estratégias de promoção e educação em saúde, visando à diminuição da incidência das doenças sexualmente transmissíveis como o HPV, e da mortalidade por câncer de colo uterino, bem como aumentar o conhecimento das mulheres acerca de seus problemas de saúde. 


\section{OBJETIVOS}

\subsection{Objetivo geral:}

Conhecer a relação entre a presença do papilomavírus humano (HPV) em mulheres e o desenvolvimento do câncer de colo uterino.

\subsection{Objetivos específicos:}

- Traçar estratégias de promoção e educação em saúde, visando à diminuição da incidência de doenças sexualmente transmissíveis (DST) e da mortalidade por câncer de colo uterino, bem como aumentar o conhecimento das mulheres acerca de seus problemas de saúde;

- Fornecer dados científicos para embasar a criação de programas de educação sexual voltados à saúde da mulher. 


\section{O PAPILOMAVÍRUS HUMANO (HPV)}

Atualmente são conhecidos mais de 100 tipos de papilomavírus humano (HPV) e destes, aproximadamente 20 genótipos infectam o trato genital. O Papilomavírus humano (HPV) é um DNA - vírus do grupo papovírus. Estes vírus estão divididos em dois grupos, de acordo com seu potencial oncogênico. Os tipos de alto risco, potencialmente oncogênicos, quando associados a outros fatores são responsáveis pelo surgimento das neoplasias intraepiteliais cervicais, do câncer invasor do colo uterino, da vulva, da vagina e da região anal (BRASIL, 2006, p.87).

Segundo Silva et. al. (2006) os tipos de HPV são subdivididos de acordo com seu potencial oncogênico em baixo e alto risco. Os tipos 6, 11, 42, 44, 70 e 73 são considerados de baixo risco e os tipos $16,18,31,33,34,35,39,45,51,56,58,59,66$, e 68 de alto risco oncogênico.

Rosa et al.(2009) afirmou que o HPV-16 e o HPV-18 estão presentes em 70\% das biópsias realizadas em pacientes com diagnóstico de câncer cervical e que nenhum outro fator de risco para neoplasia cervical tem magnitude comparável. Afirmou ainda que a infecção pelo HPV isoladamente, apesar de ser fator importante, não é suficiente para desencadear o processo carcinogênico.

\subsection{Infecção pelo papilomavírus humano (HPV)}

A maior parte das infecções pelo HPV são inaparentes ou assintomáticas. Algumas podem manifestar-se sob a forma de lesões exofíticas que são conhecidas como condiloma acuminado, verrugas genitais ou popularmente como crista de galo. A forma subclínica pode ser detectada pela citologia oncótica, por meio de testes moleculares como a reação em cadeia de polimerase (PCR) e outras técnicas moleculares. Na forma clínica condilomatosa, as lesões podem ser únicas ou múltiplas, restritas ou difusas e de tamanho variável, localizando-se na mulher na vulva, períneo, região perianal, vagina e colo (BRASIL, 2006, p.87).

Segundo Cavalcanti e Carestiato (2006) a infecção genital pelo HPV manifesta-se de três formas: verrugas anogenitais (condilomas), infecção latente ou inativa e infecção ativa, estando esta última relacionada aos tipos de HPV potencialmente oncogênicos, responsáveis pela persistência da infecção e pelo surgimento das neoplasias intra-epiteliais. De acordo com as mesmas autoras, alguns estudos demonstraram que $70 \%$ das infecções por HPV são 
eliminadas espontaneamente pelo organismo dentro de um ano, e que esta percentagem de remissão aumenta para 91\%, dentro de dois anos. No entanto, afirmam que as infecções que persistem após este período, estão associadas à progressão para o câncer cervical.

\subsection{Transmissão}

Segundo Rosa et al. (2009) o HPV pode ser transmitido durante a prática sexual pelo contato direto entre os órgãos genitais, pelo sexo oral e anal.

Além da transmissão sexual, o HPV pode ser transmitido verticalmente, da mãe para o filho e raramente por fômites. O vírus pode permanecer por muito tempo no estado latente, no entanto, não se conhece a duração deste período de latência e que fatores contribuem para o surgimento das lesões condilomatosas (BRASIL, 2006, p.87).

\subsection{Diagnóstico}

O condiloma acuminado é diagnosticado clinicamente e em alguns casos pode ser confirmado por biópsia. As lesões subclínicas cervicais são geralmente detectadas por citologia oncótica, devendo ser mais bem avaliadas por colcoscopia, teste de Schiller (iodo) e biópsias dirigidas. O diagnóstico definitivo da infecção pelo HPV é feito pela identificação da presença do DNA viral por meio de testes moleculares como o PCR e a captura híbrida. (BRASIL, 2006, p.88).

Cavalcanti e Carestiato (2006) apontam que a primeira forma de detecção de alterações compatíveis com a infecção por HPV foi a coloração feita pelo exame de Papanicolaou, no entanto, o teste apresenta um número elevado de resultados falso-negativos. Afirmam que a colposcopia, exame que permite melhor visualização do colo uterino, é um exame de extremo valor para a detecção de lesões causadas pelo HPV e que durante o procedimento, lesões suspeitas podem ser coletadas para biópsia.

Com o desenvolvimento tecnológico, várias técnicas moleculares foram desenvolvidas, permitindo maior sensibilidade no diagnóstico da infecção pelo HPV, bem como determinar qual o genótipo prevalente, contribuindo desta forma para o diagnóstico precoce e para a prevenção do câncer uterino. 


\subsection{Tratamento}

O objetivo principal do tratamento da infecção pelo HPV é a remoção das lesões condilomatosas, o que leva a cura a maioria dos pacientes. Não há evidências que indicam que os tratamentos disponíveis para o HPV erradicam ou afetam a história natural da infecção pelo vírus, já que mesmo sem tratamento, os condilomas podem desaparecer, aumentar de tamanho ou de número, ou ainda, permanecer inalterados. As verrugas localizadas em áreas úmidas ou em superfícies intertriginosas, respondem melhor a terapêutica tópica com a aplicação do ácido tricloroacético (ATA) ou podofilina. (BRASIL, 2006, p.47).

Para a remoção das lesões condilomatosas são utilizados meios químicos, físicos e cirúrgicos, de acordo com cada caso. Os meios químicos destroem as lesões por meio da aplicação direta de substâncias químicas sobre os condilomas, sendo que os mais utilizados são: a podofilina a $25 \%$ e o ácido tricloracético a $80 \%$. Os meios físicos como a crioterapia promovem a destruição térmica do epitélio, por meio de dispositivos metálicos resfriados por CO2 e que aplicados diretamente nas lesões promovem a citólise térmica dos condilomas, a eletrocauterização que destrói as lesões por meio da aplicação de um cautério quente sobre o colo uterino, a vaporização a laser e por último a exérese cirúrgica, que consiste na retirada cirúrgica dos condilomas (BRASIL, 2006, p. 47-49).

\subsection{Prevenção}

A Educação e a Promoção da Saúde continuam sendo uma das práticas mais eficazes na prevenção da infecção pelo HPV e por outras DST. A realização periódica do exame citológico, a adoção de práticas sexuais seguras, evitar comportamentos de risco e buscar o conhecimento acerca da doença e dos modos de transmissão são medidas preventivas de grande importância no combate ao câncer cervical. Além disso, ao prevenir a infecção pelo HPV, estaremos contribuindo para a diminuição na incidência do câncer de colo uterino e em conseqüência nos índices de mortalidade por este tipo de neoplasia.

\subsection{Epidemiologia do HPV}

A associação entre o papilomavírus humano (HPV) e o câncer de colo uterino é aproximadamente 10 a 20 vezes maior do que o tabagismo e o câncer de pulmão (BRASIL, 2002, p.15). 
Segundo Cavalcanti e Carestiato (2006) evidências epidemiológicas e moleculares indicam claramente que certos tipos de HPV são a principal causa de câncer cervical, sendo que estes são identificados em 95 a 100\% dos cânceres cervicais. Afirmam ainda que a Organização Mundial de Saúde já reconhece este vírus como agente etiológico responsável pelo surgimento do câncer uterino.

Ainda de acordo com Cavalcanti e Carestiato (2006) a infecção genital pelo HPV é mais comum em mulheres jovens sexualmente ativas, entre 18 e 30 anos, sendo que após os 30 anos esta incidência tende a diminuir. Todavia, afirmam que a incidência do câncer cervical acomete mais mulheres entre 45 e 49 anos de idade.

\subsection{Vacinas contra o HPV}

Sabe-se que existem atualmente duas vacinas contra o papilomavírus humano (HPV), dos genótipos mais prevalentes na oncogênese cervical. Existem discussões a respeito de se implantar estas vacinas na rede pública de saúde. No entanto, esta possibilidade nos parece um pouco remota, visto que mesmo sendo a pneumonia uma das principais causas de internação entre crianças, a vacina pneumocócica ainda não foi inserida no calendário básico, do Programa Nacional de Imunização. Além disto, a vacina contra o HPV apresenta custo elevado, além do que, estudos sobre custo-efetividade levarão anos para serem concluídos.

Rosa et. al. (2009) levanta alguns questionamentos relevantes em relação à imunização contra o HPV. A autora questiona sobre qual seria a duração da imunidade conferida pela vacina, qual a eficácia sobre os outros sorotipos de HPV, se há algum teste sorológico para detecção da imunidade, sobre a negligência na realização do exame papanicolaou, que segundo ela poderia ser delegado a um segundo plano e ainda até que ponto as mulheres vacinadas contribuirão para o aumento de outras doenças sexualmente transmissíveis ao se sentirem protegidas contra o HPV. A autora questiona ainda o alto custo da vacina e se os homens também deverão ser vacinados. 


\section{CÂNCER CERVICAL}

\subsection{Manifestações Clínicas}

O câncer de colo do útero é uma doença de crescimento lento e silencioso, uma afecção progressiva iniciada com transformações intra-epiteliais progressivas importantes, porém inicialmente assintomática, podendo evoluir para um processo invasor num período que varia de 10 a 20 anos, quando a cura se torna mais difícil, se não impossível. No estágio invasor os principais sintomas são sangramento vaginal, corrimento fétido e dor (BRASIL, 2002, p.17).

O carcinoma de colo é o câncer predominantemente de células escamosas, sendo que 10 \% são adenocarcinomas. Existem vários tipos de câncer de colo e muitos deles se originam em células escamosas, enquanto o restante são adenocarcinomas que atingem as glândulas produtoras de muco e o seu surgimento está associado à infecção pelo HPV. Na fase inicial passa quase imperceptível e na fase avançada pode causar sangramento e secreção aumentada de odor fétido, devido à necrose e infecção do tumor. Com a evolução da doença outros sintomas surgem como: dores nas pernas, disúria, sangramento retal e edema dos membros (SMELTZER; BARE, 2005, p.1511-1512).

\subsection{Epidemiologia do câncer cervical}

O câncer cervical é o segundo câncer mais freqüente entre mulheres, com aproximadamente 500 mil casos novos por ano no mundo, sendo responsável pelo óbito de aproximadamente 230 mil mulheres por ano. Sua incidência é cerca de duas vezes maior em países menos desenvolvidos quando comparada aos países desenvolvidos (BRASIL, 2009, p.33).

Apesar de apresentar um alto potencial de cura, o câncer de colo de útero continua sendo uma das principais causas de morte por câncer no Brasil. Mesmo com a alta cobertura de mulheres que realizam o exame de papanicolaou, não foi observado ainda queda no percentual de mortalidade por câncer uterino (BRASIL, 2002, p.5).

Segundo estimativa do Instituto Nacional de Câncer, o número de casos novos de câncer de colo uterino esperados para o ano de 2010 no Brasil será de 18.430 (dezoito mil, 
quatrocentos e trinta), com um risco estimado de 18 casos a cada 100 mil mulheres (BRASIL, 2009, p.32).

\subsection{Co-fatores no surgimento do câncer cervical}

Além da infecção pelo HPV, outros fatores influenciam na oncogênese cervical como: o tabagismo, multiplicidade de parceiros sexuais, uso de contraceptivos orais, multiparidade, baixa ingestão de vitaminas, iniciação sexual precoce e co-infecção por agentes infecciosos como o vírus da imunodeficiência humana (HIV) e Chlamydia trachomatis (BRASIL, 2009, p.33).

Apesar de ser um fator de risco importante para o desenvolvimento das neoplasias cervicais, estudos demonstram que o HPV sozinho não é suficiente para levar ao surgimento do câncer cervical. A associação do HPV com outros fatores como: presença de outras doenças sexualmente transmissíveis (DST), presença do HIV, imunossupressão e tabagismo, também têm influência no processo de oncogênese cervical.

\subsection{Tratamento}

O tratamento das lesões cervicais pré-neoplásicas e neoplásicas varia de acordo com cada situação e pode ser realizado por diversas técnicas físicas, químicas, cirúrgicas e ainda por radioterapia e quimioterapia. O tratamento químico visa destruir as lesões por meio da aplicação direta de substâncias químicas como: podofilina a 25\%, o fluorouracil a 5\% e o ácido tricloroacético (ATA) a 70\%. Os meios físicos compreendem: a crioterapia, a eletrocauterização e o laser de dióxido de carbono que é utilizado para vaporizar o tecido ou mesmo para cortá-lo. Os tratamentos cirúrgicos têm como objetivo evitar a disseminação do tumor para outros locais, obter informações sobre a natureza do tumor, oferecendo subsídios importantes para o prognóstico e a terapêutica adjuvante e proporcionar mutilação mínima. As técnicas cirúrgicas compreendem: cirurgia de alta freqüência (CAF) para lesões préneoplásicas, o método de cone a frio que é indicado tanto para diagnóstico, quanto para terapêutica de lesões precursoras de alto grau (NIC II e NIC III), e por fim a histerectomia, que consiste na retirada do útero, indicada para mulheres com carcinoma microinvasor e que já têm prole definida. A radioterapia amplamente utilizada como terapêutica para o câncer de colo de útero, consiste na eliminação ou redução do tumor por meio da emissão de elétrons acelerados ou raios gama, emitidos pelo radium ou outros materiais radioativos. Mesmo não sendo um tratamento de escolha para o carcinoma escamoso, o uso da quimioterapia 
concomitante à radioterapia tem aumentado a resposta individual à terapêutica do câncer cervical (BRASIL, 2002, p. 47- 53).

Devido a sua magnitude, o câncer do colo uterino constitui-se hoje em um problema de Saúde Pública. Apesar de ser uma doença previsível e totalmente passível de cura, desde que detectada precocemente, este tipo de câncer continua sendo uma das maiores causas de mortalidade entre mulheres. 


\section{METODOLOGIA}

Considerando todos os aspectos destacados e com o objetivo de analisar a relação entre a presença do papilomavírus humano (HPV) em mulheres e o surgimento do câncer de colo uterino, utilizou-se a metodologia de pesquisa qualitativa que tem por desígnio proporcionar maior proximidade com o problema, com vista a torná-lo mais claro. "O planejamento para este tipo de trabalho é bastante flexível, de modo que possibilite a consideração dos mais variados aspectos relativos ao fato estudado" (GIL, 2002, p. 41).

Tal procedimento metodológico permitiu a avaliação e comparação de dados de pesquisas realizadas recentemente.

Assim, para a elaboração deste estudo, pesquisou-se artigos científicos no portal Scielo Brasil, publicados no período de 1999 a 2009, sobre a associação entre papilomavírus humano e o desenvolvimento do câncer de colo uterino. Para a seleção dos artigos optou-se por aqueles que cruzassem duas ou mais das seguintes palavras chaves: papilomavírus humano (HPV), oncogênese, câncer cervical, carcinoma cervical, neoplasia cervical, colo uterino. Desta forma, doze artigos científicos foram selecionados para revisão bibliográfica.

As análises obtidas foram transcritas na forma de texto e tabelas. Tais resultados seguem no próximo capítulo. 


\section{RESULTADOS E DISCUSSÃO}

Os resultados obtidos estão descritos na tabela 01.

Tabela 01 - Resultados da revisão bibliográfica (1999-2009).

\begin{tabular}{|c|c|c|c|}
\hline Autores & Título & Palavras-chaves & Ano \\
\hline ROSA et. al. & $\begin{array}{l}\text { Papilomavírus humano e } \\
\text { neoplasia cervical. }\end{array}$ & $\begin{array}{l}\text { Neoplasia intra-epitelial cervical, } \\
\text { infecções por papilomavírus, vírus } \\
\text { DNA. }\end{array}$ & 2009 \\
\hline RAMA et. al. & $\begin{array}{l}\text { Prevalência do HPV em mulheres } \\
\text { rastreadas para o câncer } \\
\text { cervical. }\end{array}$ & $\begin{array}{l}\text { Infecções por papilomavírus, } \\
\text { epidemiologia, neoplasias do colo } \\
\text { do útero, prevenção e controle, } \\
\text { fatores de risco, estudos } \\
\text { transversais. }\end{array}$ & 2008 \\
\hline $\begin{array}{l}\text { FERNANDES } \\
\text { et. al. }\end{array}$ & $\begin{array}{l}\text { Human papillomavirus infection } \\
\text { in women attended at a cervical } \\
\text { cancer screening service in } \\
\text { Natal, Brazil. }\end{array}$ & $\begin{array}{l}\text { Human papillomavirus, cervical } \\
\text { cancer, epidemiology, prevalence, } \\
\text { risk factors. }\end{array}$ & 2008 \\
\hline JUNIOR et al. & $\begin{array}{l}\text { Associação entre a carga viral de } \\
\text { HPV de alto risco, expressão de } \\
\text { p16 }{ }^{I N K 4 a} \text { e lesões intra-epiteliais } \\
\text { escamosas do colo uterino }\end{array}$ & $\begin{array}{l}\text { HPV, câncer de colo uterino, } \\
\text { biomarcadores do câncer cervical, } \\
\text { P16, carga viral. }\end{array}$ & 2007 \\
\hline TÚLIO et. al. & $\begin{array}{l}\text { Relação entre a carga viral de } \\
\text { HPV oncogênico determinada } \\
\text { pelo método de captura híbrida e } \\
\text { o diagnóstico citológico de lesões } \\
\text { de alto grau. }\end{array}$ & $\begin{array}{l}\text { Papilomavírus humano (HPV), } \\
\text { neoplasia intra-epitelial cervical } \\
\text { (NIC), captura híbrida, } \\
\text { papanicolaou, DNA-citoliq. }\end{array}$ & 2007 \\
\hline $\begin{array}{l}\text { FREITAS et } \\
\text { al. }\end{array}$ & $\begin{array}{l}\text { Molecular detection of HPV } 16 \\
\text { and } 18 \text { in cervical samples of } \\
\text { patients from Belo Horizonte, } \\
\text { Minas Gerais, Brazil. }\end{array}$ & $\begin{array}{l}\text { HPV, cervical cancer, } P C R, \\
\text { genotipyping, citology. }\end{array}$ & 2007 \\
\hline $\begin{array}{l}\text { DELUCA et } \\
\text { al. }\end{array}$ & $\begin{array}{l}\text { Human papillomavirus genotypes } \\
\text { in women with cervical } \\
\text { cytological abnormalities from } \\
\text { an area with high incidence of } \\
\text { cervical cancer. }\end{array}$ & $\begin{array}{l}\text { HPV; cervical cancer; } \\
\text { Papillomavirus; PCR-RFLP. }\end{array}$ & 2004 \\
\hline
\end{tabular}




\begin{tabular}{|l|l|l|c|}
\hline BORGES et al. & $\begin{array}{l}\text { Taxa de detecção do } \\
\text { papilomavírus Humano pela } \\
\text { captura híbrida II, em mulheres } \\
\text { com neoplasia intra-epitelial } \\
\text { cervical. }\end{array}$ & $\begin{array}{l}\text { Papilomavírus humano, captura } \\
\text { híbrida II, neoplasia intra-epitelial } \\
\text { cervical, colo lesões pré- } \\
\text { neoplásicas. }\end{array}$ & 2004 \\
\hline $\begin{array}{l}\text { CAMARA et. } \\
\text { al. }\end{array}$ & $\begin{array}{l}\text { Prevalence of human } \\
\text { papillomavirus types in women } \\
\text { with pre-neoplastic and } \\
\text { neoplastic cervical lesions in the } \\
\text { Federal District of Brazil. }\end{array}$ & $\begin{array}{l}\text { Human papillomavirus (HPV); } \\
\text { genotypes ; prevalence; HPV-58; } \\
\text { cervical lesion ; Brazil }\end{array}$ & 2003 \\
\hline $\begin{array}{l}\text { RABELO- } \\
\text { SANTOS }\end{array}$ & $\begin{array}{l}\text { Human allomavirus } \\
\text { prevalence among women with } \\
\text { cervical intraephitelial neoplasia } \\
\text { III and invasive cervical cancer } \\
\text { from Goiania, Brazil. }\end{array}$ & $\begin{array}{l}\text { Human papillomavirus - cervical } \\
\text { neoplasia - polymerase chain } \\
\text { reaction - dot blot hybridization - } \\
\text { prevalence - Goiás - Brazil }\end{array}$ & 2003 \\
\hline PINTO et. al. & $\begin{array}{l}\text { Co-fatores na oncogênese } \\
\text { cervical. }\end{array}$ & $\begin{array}{l}\text { Papilomavírus, câncer cervical, } \\
\text { imunossupressão, fumo, } \\
\text { contraceptivos orais. }\end{array}$ & 2002 \\
\hline NORONHA et. \\
al.
\end{tabular}

Fonte: Scielo Brasil

Rosa et. al.(2009) estudou a magnitude do câncer cervical que mata milhares de mulheres anualmente, principalmente nos países subdesenvolvidos (80\%) e sua relação com a presença do HPV, afirmando que nenhum outro fator de risco tem magnitude comparável. Em sua revisão bibliográfica, a autora teve como objetivo principal aumentar o conhecimento acerca do papel do HPV na etiologia do câncer cervical. Em seu estudo demonstrou os tipos de HPV prevalentes na etiopatogênese do câncer cervical em diversos países, sendo que no Brasil, afirmou que o HPV-16 predomina nos cânceres cervicais das regiões Sul (52\%), Centro oeste (57\%), Nordeste (59\%), Norte (43,5\%) e Sudeste (52\%) e já o HPV-18 aparece em segundo lugar, exceto na região centro-oeste, que o mais prevalente é o HPV-33 e nordeste, o HPV-31. Afirmou ainda que a persistência da infecção pelo HPV é que leva ao aparecimento das neoplasias intra-epiteliais cervicais: NIC I, II e III; e que a presença dos tipos oncogênicos como o HPV-16 e HPV-18 contribuem para esta persistência, visto que 70\% dos cânceres cervicais são causados por estes dois genótipos. 
Em seu trabalho, a autora salientou a importância do papilomavírus humano, em especial o HPV-16 e o HPV-18, na persistência da infecção e conseqüentemente no desenvolvimento do câncer cervical, no entanto, afirmou que isoladamente o HPV não pode levar ao surgimento do câncer uterino e que a presença de alguns co-fatores também tem influência na oncogênese cervical.

Rama et. al. (2008) afirmou que as mulheres que apresentam infecção persistente por tipos virais de alto risco do HPV são consideradas como o verdadeiro grupo de risco para o desenvolvimento do câncer cervical.

Foram analisadas 2300 mulheres de 15 a 65 anos que realizaram rastreamento para câncer cervical entre fevereiro de 2002 a março de 2003, em São Paulo e Campinas, estado de São Paulo. As amostras foram analisadas para os tipos de HPV de alto risco e a prevalência destes em toda amostra foi de 17,8\%. Os resultados citológicos foram normais em 90,5\% das amostras e 8,8\% apresentaram alterações citológicas. O teste de captura híbrida, para a detecção da presença do HPV foi positivo em 14,3\% das amostras que tiveram resultado citológico normal e em 52,4 \% das amostras que apresentaram quaisquer alterações citológicas. A prevalência em toda a amostra de infecção genital pelo HPV foi de 17,8\% (RAMA; et al., 2008).

Observa-se neste estudo que a prevalência global do HPV foi de 17,8\% entre as mulheres com e sem alterações citológicas, sendo que mais da metade das amostras que alteradas (52,4\%) foram positivas para o HPV oncogênico, comprovando a forte associação entre a presença do HPV de alto risco e a oncogênese cervical. Além disso, constatou-se que mesmo em mulheres com citologia normal houve a presença do HPV oncogênico, confirmando a importância de se conhecer melhor os mecanismos envolvidos na oncogênese cervical, visando o diagnóstico precoce e a prevenção do câncer uterino.

Fernandes et al. (2008) realizou um estudo no Hospital de Antônio Luiz , em NatalRN, durante o período de abril de 2000 a junho de 2001, sobre a infecção por HPV em mulheres atendidas em um serviço de prevenção ao câncer de colo de útero. A amostra estudada era composta por 202 (duzentas e duas) mulheres com faixa etária entre 15 e 64 anos. O objetivo do trabalho era determinar a prevalência de HPV e identificar os genótipos mais freqüentes e os fatores de risco para HPV em mulheres inscritas no programa de rastreio de câncer cervical

As mulheres foram divididas em dois grupos, de acordo com o resultado da citologia oncótica. Em um grupo ficaram as mulheres com citologia normal ou apenas com alterações benignas, totalizando 110 mulheres $(54,5 \%)$. No outro grupo ficaram as mulheres com 
alterações citológicas, totalizando 92 mulheres (45,5\%). Das mulheres que apresentaram alterações citológicas, 78 (38,6\%) apresentavam lesões intra-epiteliais escamosas de baixo grau (L-SIL) e 14 (6,9\%) apresentavam lesões intra-epiteliais escamosas de alto grau (H-SIL). No primeiro grupo (citologia normal), a presença do HPV ocorreu em 27 amostras (24,5\%), sendo que em 21 amostras (77,8\%) havia a presença de um único tipo de HPV e em 6 amostras (22,2\%) havia dois tipos ao mesmo tempo. No segundo grupo, o qual havia presença de alterações citológicas, o HPV esteve presente em 55 (cinqüenta e cinco) amostras (59,8\%), sendo que em 37 (trinta e sete) amostras (67,3\%) havia a presença de um único tipo e em 18 (dezoito) amostras havia dois tipos de HPV (32,7\%). A partir dos dados obtidos, dos genótipos de HPV identificados, quase todos pertencem ao grupo de alto potencial oncogênico. O HPV-16 foi o genótipo mais prevalente em ambos os grupos, seguido do HPV58. Havia co-infecção pelo HPV 56 e 57 em 1,8 \% dos casos de citologia normal e 8,7 \% dos casos de citologia alterada. (FERNANDES; et al., 2008).

Foi possível observar neste estudo a alta prevalência do HPV oncogênico nas amostras com alterações cervicais (59,8\%), em especial o HPV 16 e o HPV 58, confirmando o papel do HPV de alto risco na oncogênese cervical. Além disto, é preocupante a prevalência de genótipos oncogênicos nas citologias normais (24,5\%).

Junior et al. (2007) realizou um estudo sobre a associação entre a carga viral de HPV de alto risco, a expressão de $\mathrm{P} 16^{\mathrm{INK} 4_{\mathrm{A}}}$ e lesões intra-epiteliais escamosas do colo uterino. $\mathrm{O}$ autor afirma que vários estudos evidenciam a associação do HPV com o surgimento das lesões pré-invasoras e invasoras do colo do útero e que o HPV 16 ainda é o mais prevalente em todo o mundo. O autor realizou um estudo transversal pela análise de 109 amostras de biópsias de colo uterino, sendo que 57 não apresentavam alterações citológicas (52,2\%), e 52 amostras (47,8\%) apresentavam alguma alteração citológica. Dentre as alteradas, 26 apresentavam lesões intra-epiteliais escamosas de baixo grau (L-SIL) e 26 apresentavam lesões intra-epiteliais escamosas de alto grau (H-SIL). Dos 109 casos estudados, 63 foram positivos para DNA-HPV de alto risco, representando uma prevalência global do HPV oncogênico na amostra de 57,8\%, sendo que 96,1\% dos casos apresentavam H-SIL, 80,8\% dos casos L-SIL e 29,8\% dos casos tecido cervical normal, sem alterações citológicas.

Nota-se a prevalência do HPV de alto risco foi de 88,5\% nas citologias alteradas, chegando a 96,1\% dos casos de lesões intra-epiteliais cervicais de alto grau (H-SIL), corroborando os achados mundiais sobre a importância da prevalência do HPV de alto risco no surgimento das lesões pré-neoplásicas e neoplásicas. 
Túlio et al. (2007) estudou 982 (novecentas e oitenta e duas) amostras cervicovaginais de mulheres com idade compreendida entre 16 e 67 anos, durante o período de janeiro de 2001 a setembro de 2004, com o objetivo de avaliar a associação entre a carga viral de HPV oncogênico (alto risco) e o diagnóstico de lesões de alto grau (NIC II e III) pelo exame de papanicolaou ou convencional e o exame citológico em base líquida.

Das 982 amostras analisadas, 314 mulheres (32\%) apresentaram resultado citológico negativo. Destas, 226 lâminas (72\%) mostraram-se negativas para DNA-HPV. Entre estas, 88 (28\%) demonstraram a presença do DNA-HPV pela técnica de captura híbrida. Um total de 668 amostras (68\%) apresentou alterações citológicas. Dentre as alteradas, 261 apresentaram células escamosas atípicas de significado indeterminado (ASCUS), sendo que em 148 (56,7\%) havia a presença do DNA-HPV. Das 210 amostras com NIC I, em 152 amostras havia a presença HPV de alto risco (72,3\%). Das 197 amostras com NIC II ou III, 86 amostras (43,6\%) foram positivas para HPV de alto risco (TÚLIO; et al.,2007).

Foi possível reparar que entre as mulheres com alterações citológicas deste estudo, a prevalência do HPV de alto risco foi de 57,8 \%, sendo que esta prevalência foi maior nas mulheres que tinham NIC I (72,3\%). Em toda a amostra, considerando os resultados normais e alterados, a prevalência global do HPV de alto risco foi de 48,2\%.

Freitas et al.(2007) investigou a freqüência do HPV 16 e HPV 18 em 173 amostras cervicais de pacientes atendidas em dois serviços públicos de Belo Horizonte, Minas Gerais. Neste estudo foi detectada a presença do DNA-HPV em 94,4\% das citologias com lesões escamosas intra-epiteliais e/ou invasoras. Entre as amostras sem alterações citológicas a presença do HPV foi de 25,4\%. O HPV 16 foi encontrado em 20\% dos casos de lesões intraepiteliais de baixo grau (L-SIL) e em 40 \% dos casos de lesão intra-epitelial de alto grau (HSIL) e em $50 \%$ dos casos de carcinoma escamoso invasor.

Observa-se que o HPV 16 foi o tipo de papilomavírus mais prevalente no estudo e também foi possível notar que de acordo com a elevação da gravidade da lesão cervical ocorre também aumento da prevalência do HPV de alto risco: L-SIL (20\%), H-SIL (40\%) e carcinoma invasor (50\%). A prevalência do HPV 16 nas citologias sem alteração também se mostrou elevada $(25,4 \%)$.

Deluca et al. (2004) estudou 53 mulheres que procuraram o serviço de ginecologia do Hospital JR Vida em Corrientes na Argentina, entre agosto de 2001 a agosto de 2002, e que apresentaram qualquer lesão histopatológica. Entre as mulheres estudadas, três apresentavam células atípicas de significado indeterminado (ASCUS), 36 (trinta e seis) lesão intra-epitelial 
cervical de baixa qualidade (L-SIL), cinco apresentavam lesão epitelial cervical de alta qualidade (H-SIL) e 09 (nove) câncer uterino.

Dos casos de ASCUS, dois foram positivos para DNA-HPV (66,6\%), dos casos de HSIL em 19 foram encontrados DNA- HPV (52,7\%), dos casos de L-SIL, quatro foram positivos (80\%) e dos nove casos de cânceres cervicais, nove foram positivos para HPV de alto risco (100\%). A prevalência global do HPV na amostra foi de 64 \% (34 casos), sendo que o HPV 16 foi o genótipo mais freqüente, representando 32,3 \% dos casos, seguido do HPV 58, com 14,7 \% (DELUCA et al., 2007).

Pode-se ressaltar neste estudo que a associação entre HPV e câncer cervical foi bastante expressiva, visto que em nove dos nove casos de câncer havia a presença do HPV (100\%), evidenciando desta forma a importância do papel do HPV de alto risco na oncogênese cervical.

Borges et al.(2004) avaliou a taxa de detecção do papilomavírus humano (HPV) de alto risco oncogênico em 110 mulheres com neoplasia intra-epitelial cervical (NIC), com idade entre 15 e 71 anos, e verificou ainda se existe associação entre a presença do vírus e a carga viral com a gravidade da lesão cervical, no período de abril de 1999 a setembro de 2000. A taxa global de prevalência do HPV de alto risco no estudo foi de 77,3\%. Nas mulheres que apresentaram NIC I esta prevalência foi de 100\%. Nas mulheres com NIC II ou NIC III foram identificados HPV de alto risco em 85,9 \% das amostras. Nas mulheres onde não foi detectada a presença de neoplasias intra-epiteliais a prevalência do HPV de alto risco foi de $44 \%$.

Analisa-se neste estudo a alta prevalência do HPV de alto risco entre as mulheres com NIC I (100\%) e nas mulheres sem neoplasias (44\%). Alguns estudos sugerem que estas mulheres têm risco aumentado de progredir para outros tipos neoplasias mais graves, como o NIC II ou III. O achado nas mulheres com NIC II ou NIC III também foi bastante significativo em relação à associação do HPV de alto risco e a oncogênese cervical.

Rabelo-Santos et al.(2003) afirma que estudo biológico internacional sobre câncer cervical mostrou que 92,9 \% dos casos de câncer cervical em 22 países continham o DNAHPV, variando entre 75 e 100 \%. O objetivo deste estudo foi determinar a prevalência de diferentes tipos de HPV entre mulheres com NIC III (neoplasia intra-epitelial cervical) e câncer invasivo, submetidas à histerectomia no hospital Araújo Jorge, na cidade de GoiâniaGoiás, entre novembro de 1997 e novembro de 1998.

A amostra era composta por 86 mulheres, no entanto, doze tiveram que ser excluídas por não poderem ser avaliadas. Das 74 amostras restantes, 18 tinham NIC III, 04 tinham 
adenocarcinoma, 03 tinham carcinomas indiferenciados, 48 tinham carcinomas epidermóides, e uma apresentava carcinoma adenoescamoso. A prevalência global do HPV na amostra foi de 76 \%. Em geral, a maior prevalência foi a do HPV 16, seguido do HPV 33, 18 e 31. Nos casos de carcinoma epidermóide a prevalência do HPV chegou a 79\%, sendo que o HPV 16 foi detectado em 71\% dos casos, ficando o HPV 33 em segundo lugar. Nos casos de NIC III a prevalência do HPV foi de 61 \%, sendo que o HPV 16 foi o primeiro mais prevalente. Nos adenocarcinomas o HPV 16 ficou em primeiro lugar, seguido do HPV 18. O único caso de carcinoma adenoescamoso foi negativo para HPV. Três casos de carcinomas indiferenciados foram positivos para HPV-DNA (100\%), sendo que dois deles foram de HPV 16 (75\%) (RABELO-SANTOS; et al., 2003).

Constatou-se que a prevalência global do HPV na amostra foi de 76 \%, alcançando 79 \% nos casos de carcinoma epidermóide. O HPV 16 ocorreu em 71 \% dos casos com carcinoma epidermóide e este tipo de HPV também foi o mais prevalente nos adenocarcinomas e carcinomas indiferenciados. No entanto, contrariando os diversos dados mundiais, no único caso de carcinoma adenoescamoso da amostra, não houve a presença do HPV. Uma possível explicação para este achado é a ocorrência de resultados falso-negativos em cânceres invasivos, constatada em estudos recentes, conforme levantado pelo próprio autor.

Camara et al. (2003) afirmaram que alguns tipos de HPV já são considerados como agentes oncogênicos cervicais e que a infecção crônica por estes tipos está indiscutivelmente relacionada com o surgimento do câncer cervical. Em seu estudo descreveu a prevalência dos tipos de HPV em 129 (cento e vinte e nove) amostras citológicas com alterações, de mulheres atendidas em clínicas ginecológicas de três hospitais públicos do Distrito Federal, no período de outubro de 1998 a agosto de 2001.

Foram incluídos na pesquisa os resultados que apresentaram NIC I, II e III, carcinoma escamoso, adenocarcinoma, células escamosas atípicas de significado indeterminado (ASCUS) e alterações citológicas sugestivas de HPV. As lesões cervicais diagnosticadas foram divididas em dois grupos, de acordo com a gravidade da lesão. No grupo 1 (G1) ficaram as neoplasias cervicais intra-epiteliais (NIC) II e III, o adenocarcinoma e o carcinoma epidermóide. No grupo 2 (G2) ficaram as células escamosas atípicas de significado indeterminado (ASCUS), as neoplasias intra-epiteliais cervicais (NIC) I, as células glandulares atípicas de significado indeterminado (ASGUS) e as lesões cervicais sugestivas de HPV.(CAMARA; et al., 2003). 
O G1 representava 95 (noventa e cinco) amostras, sendo que a prevalência de HPV neste grupo foi de 66,3\%. O G2 continha 34 (trinta e quatro) amostras e a prevalência do HPV neste grupo foi de 50\%. A prevalência global do HPV nas duas amostras foi de 62\% (80/129). A prevalência do HPV-16 no G1 foi 56,8\% e no G2 foi 25 \%. No G2 o HPV-58 ocupou o segundo lugar juntamente com o HPV-53 e o HPV-18, com prevalência de 12,5\% cada um. No G1 o HPV-31 foi o segundo mais prevalente com 15,7 \% e o HPV-58 ficou em terceiro lugar com uma prevalência de 13,7 \%. Os genótipos mais prevalentes na amostra total foram: HPV-16 (49,2\%), HPV-58 (13,4 \%) e HPV-31 (11,9\%) (CAMARA; et al., 2003).

Observou-se neste estudo que a prevalência global do HPV nos dois grupos foi 62 \%, sendo o HPV 16 o mais prevalente, seguido do HPV 58. No grupo 1 a prevalência do HPV foi de $66,3 \%$ e a do grupo 2 de $50 \%$. Os dados obtidos estão em conformidade com a literatura a respeito do papel oncogênico do HPV, visto que no grupo 1 onde se concentra as lesões cervicais mais graves (adenocarcinoma, carcinoma epidermóide, NIC II e III) a prevalência do HPV foi maior (66,3\%), especialmente a do HPV 16, reconhecido como de alto risco, que representou $56,8 \%$ dos casos.

Pinto et al. (2002) afirma que o HPV é o principal fator causal do carcinoma escamoso cervical e que este estudo foi uma tentativa de explorar os co-fatores do HPV na oncogênese cervical. Dentre esses co-fatores no processo de oncogênese cervical o autor descreveu a relação entre a resposta imune local e humoral, a co-infecção pelo vírus HIV, fatores genéticos como o polimorfismo da proteína P53, o tabagismo e o uso de contraceptivos orais. O autor afirma ainda que neste estudo foram enfocados os fatores não virais na oncogênese cervical e que estes fatores interagem em menor ou maior intensidade com as oncoproteínas e outros elementos do HPV, relacionando-se com o vírus de forma a potencializar sua ação na célula hospedeira e facilitar o desenvolvimento dos processos de imortalização e carcinogênese.

Constatou-se pela análise deste estudo o papel fundamental do HPV na oncogênese cervical, no entanto, observou-se que outros fatores não virais também são importantes para o desenvolvimento do câncer cervical. Acredita-se que fatores como a imunossupressão, o tabagismo, e outros, interferem na forma como o papilomavírus age nas células cervicais, funcionando como mecanismos potencializadores do efeito oncogênico deste vírus.

Noronha et al. (1999) selecionou 228 (duzentos e vinte e oito) amostras de biópsias, no período de março de 1992 a maio de 1996 que apresentavam suspeita clínica ou laboratorial de processo maligno cervical e sem história de tratamento neoplásico anterior, para determinar a prevalência e identificar os tipos de HPV mais freqüentes em mulheres com 
lesões cervicais, agrupadas segundo diagnóstico histopatológico em Belém do Pará. As amostras foram distribuídas em três grupos: A, B e C, de acordo com o diagnóstico histopatológico. A idade das mulheres variou entre 16 e 86 anos.

O grupo A era composto por 155 (cento e cinqüenta e cinco) mulheres, sendo que 150 (cento e cinqüenta) apresentavam carcinoma epidermóide invasor e 05 (cinco) adenocarcinoma. Entre os casos de adenocarcinomas 04 (quatro) amostras apresentavam HPV (80\%) e entre os casos de carcinoma epidermóide invasor, 105 (cento e cinco) apresentavam a presença do HPV (70\%). A prevalência global do HPV no grupo A foi de 70,3 \%. A presença do HPV-16 ocorreu em 64 amostras (60,4 \%), do HPV-18 em 12 amostras (11,3\%), HPV 31, 33, 45, 52, 58, 59 e 73 representaram juntos 18,3 \% dos casos, o HPV 73 com 0,9 \%. O grupo B era composto por 54 (cinqüenta e quatro) mulheres, das quais 53 (cinqüenta e três) apresentavam NIC III (neoplasia intra-epitelial cervical) e uma apresentava NIC II. O único caso de NIC II havia presença do HPV (100\%). Dos 53 (cinqüenta e três) casos de NIC III, 33 (trinta e três) casos apresentavam HPV (62,2\%). A prevalência geral do HPV no grupo B foi de 63 \% e a presença do HPV-16 ocorreu em 54,5 \% dos casos, o HPV-18 em 3 \%, os HPV 31, 33 e 58 apareceram em 21,2 \%. Já o grupo C era composto por 19 (dezenove) mulheres com cervicite crônica. Destas, em sete havia a presença do HPV (36,8\%). Das amostras positivas para HPV, cinco pertenciam aos seguintes tipos: 16, 18 ou 33, enquanto dois não puderam ser identificados (NORONHA; et al. 1999).

Das 228 (duzentos e vinte e oito) amostras analisadas, a presença do HPV ocorreu em 150 (cento e cinqüenta) delas, demonstrando uma prevalência global de 65,8 \%. Diante dos resultados obtidos pode-se observar o papel oncogênico do HPV, visto que nos casos de adenocarcinomas e carcinoma epidermóide invasor a prevalência do HPV foi respectivamente 80 e 70\%, sendo que o HPV 16 teve prevalência de 60,4\% e o HPV 18 11,3\%, neste grupo. A prevalência do HPV no grupo B foi de 63\%, sendo que no único caso de NIC II foi 100\% e nos casos de NIC III foi de 62,2\%. A prevalência do HPV 16 no grupo B (54,5\%) reforça o papel do HPV de alto risco na carcinogênese cervical.

Por meio desta revisão bibliográfica constatou-se que todos os autores estudados afirmaram haver relação entre a presença do papilomavírus humano e a oncogênese cervical, principalmente, os genótipos reconhecidamente oncogênicos, como o HPV-16 e o HPV-18, entre outros. Além disto, foi possível compreender melhor o papel dos co-fatores do HPV na oncogênese cervical, dado que alguns autores afirmaram que apesar de ser fator imprescindível, a infecção pelo HPV por si só, não é suficiente para levar ao surgimento do câncer cervical. 
Pela análise dos artigos e dos dados obtidos por seus autores, verificou-se que a prevalência do HPV de alto risco variou entre 52,4\% à 100\% nas amostras com alterações citológicas, e nas amostras sem alterações citológicas este percentual variou entre $14,3 \%$ à 44\%. Diante destes dados, faz-se necessário questionar a eficácia dos métodos diagnósticos tradicionais usados para rastrear as lesões precursoras do câncer cervical, visto que mesmo em mulheres com exame de papanicolaou normal, havia presença de HPV oncogênico, principal responsável pela persistência da infecção, e conseqüentemente, pelo surgimento do câncer cervical.

Deste modo, concluiu-se que é nítido o papel do HPV no processo de oncogênese cervical, no entanto, pudemos observar também que os autores além de identificarem a presença do HPV, estão buscando identificar ainda quais os tipos de HPV envolvidos na carcinogênese cervical e ainda quais co-fatores contribuem para o desencadeamento deste processo. 


\section{CONSIDERAÇÕES FINAIS}

O papel do papilomavírus humano (HPV) está bem estabelecido na oncogênese cervical, principalmente os genótipos de alto risco, responsáveis pela persistência da infecção, e conseqüentemente, pelo surgimento das lesões cervicais de alto grau e pelo desenvolvimento do câncer uterino. No entanto, ainda são pouco compreendidos os mecanismos que desencadeiam esta persistência, visto que muitas infecções pelo papilomavírus regridem espontaneamente. Além disto, é preciso dar atenção especial às mulheres com resultado citológico normal, já que entre estas mulheres, vários autores identificaram a presença do HPV de alto risco.

A partir dos dados obtidos nesta revisão bibliográfica, concluiu-se que há uma nítida relação entre a presença do HPV, em especial o HPV-16 e o HPV 18, e o desenvolvimento das lesões pré-neoplásicas e neoplásicas do colo uterino. O entendimento desta associação é de grande importância para o conhecimento dos mecanismos envolvidos na oncogênese cervical.

Sabe-se que existem atualmente duas vacinas contra o papilomavírus humano (HPV), dos genótipos mais prevalentes na oncogênese cervical. Existem discussões a respeito de se implantar estas vacinas na rede pública de saúde. No entanto, esta possibilidade parece muito remota, visto que mesmo sendo a pneumonia uma das principais causas de internação entre crianças, a vacina pneumocócica ainda não foi inserida no calendário básico do Programa Nacional de Imunização. Além disto, a vacina contra o HPV apresenta custo elevado, além do que, estudos sobre custo-efetividade levarão anos para serem concluídos.

Sendo assim, a solução mais viável é investir em políticas públicas que visem à criação de Programas de Promoção e Prevenção da saúde que ofereçam informações sobre a transmissão, os fatores de risco e a importância da realização do exame periódico para o rastreio das lesões precursoras do câncer cervical. Além disto, é preciso garantir o acesso a outros métodos diagnósticos complementares, como a colposcopia que permite melhor visualização do colo uterino e aos testes moleculares, como o PCR e a captura híbrida, eficazes na identificação do genótipo do HPV.

Deste modo, por meio de ações de promoção e educação em saúde é possível interromper a cadeia de transmissão das DST, diminuir a incidência de infecção pelo HPV, prevenir o câncer cervical, e conseqüentemente, diminuir os índices de mortalidade por esta patologia em nosso país. 


\section{REFERÊNCIAS BIBLIOGRÁFICAS}

BORGES, Sonia Cristina Vidigal et al . Taxa de detecção do papilomavírus humano pela captura híbrida II, em mulheres com neoplasia intra-epitelial cervical. Rev. Bras. Ginecol. Obstet., Rio de Janeiro, v.26, n.2, mar. 2004. Disponível em: s http://www.scielo.br/scielo.php?script=sci_arttext\&pid=S0100-

72032004000200004\&lng=pt\&nrm=iso $>$ Acessado em: 10 dez. 2009.

BRASIL. Ministério da Saúde. Instituto Nacional de Câncer. Estimativa 2010: incidência de câncer no Brasil / Instituto Nacional de Câncer. - Rio de Janeiro: INCA, 2009. 98 p. Disponível em < http://www.inca.gov.br/estimativa/2010/>. Acessado em: 18. jan 2009.

BRASIL. Ministério da Saúde. Secretaria de Vigilância em Saúde. Programa Nacional de DST/AIDS. Manual de Controle de Doenças Sexualmente Transmissíveis. 4 ed. Brasília: Ministério da Saúde, 2006. 138 p. (Série A. Normas e Manuais Técnicos).

BRASIL. Ministério da Saúde. Secretaria Nacional de Assistência à Saúde. Instituto Nacional de Câncer. Coordenação de Prevenção e Vigilância (Conprev). Falando sobre câncer do colo do útero. Rio de Janeiro: MS/INCA, 2002. 59 págs.

CAMARA, Geni NL et al. Prevalence of human papillomavirus types in women with preneoplastic and neoplastic cervical lesions in the Federal District of Brazil. Mem. Inst. Oswaldo Cruz [online]. Rio de Janeiro, vol.98, n.7, out. 2003. Disponível em: <http://www.scielo.br/scielo.php?script=sci_arttext\&pid=S0074-02762003000700003\&ln g=pt\&nrm=iso $\geq$ Acessado em: 10 dez. 2009.

CAVALCANTI, Sílvia MB; CARESTIATO, Fernanda N. Infecções causadas pelos papilomavírus humanos: atualização sobre aspectos virológicos, epidemiológicos e diagnósticos. DST - J. Bras. Doenças Sex. Transm. 18(1): 73-79, 2006. Disponível em: $\leq$ http://www.uff.br/dst/revista18-1-2006.htm >. Acessado em: 18 jan. 2010.

DELUCA, Gerardo Daniel et al. Human papillomavirus genotypes in women with cervical cytological abnormalities from an area with high incidence of cervical cancer. Rev. Inst. Med. trop. S. Paulo [online]. 2004, vol. 46, n.1, pp. 9-12. Disponível em: < http://www.scielo.br/scielo.php?script=sci_arttext\&pid=S0036-46652004000100002\&l

ng=pt\&nrm=iso. $\quad>\quad$ Acessado em: $10 \quad$ dez.


FERNANDES, Thales Allyrio Araújo de Medeiros et al . Human papillomavirus infection in women attended at a cervical cancer screening service in Natal, Brazil. Braz. J. Microbiol., São Paulo, v. 39, n. 3, set. 2008. Disponível em: $<$ http://www.scielo.br/scielo.php?script=sci_arttext\&pid=S151783822008000300031\&lng=pt\&nrm=iso>. Acessado em: 10 dez. 2009.

FREITAS, Taíse Palmeiras et al . Molecular detection of HPV 16 and 18 in cervical samples of patients from Belo Horizonte, Minas Gerais, Brazil. Rev. Inst. Med. trop. S. Paulo, São Paulo, v.49, n.5, out. 2007. Disponível em: < www.scielo.br/scielo.php?script=sci_arttext\&pid=S003646652007000500005\&lng=pt\&nrm=iso $>$ Acessado em: 10 dez. 2009.

GIL, Antônio Carlos. Como Elaborar Um Projeto de Pesquisa. 4. ed. - São Paulo: Atlas. 2002. p. 41- 42.

JUNIOR, Eleutério Jose et al. Associação entre a carga viral de HPV de alto risco, expressão de $\mathrm{p} 16^{\text {INK4a }}$ e lesões intra-epiteliais escamosas do colo uterino. Rev. Assoc. Med. Bras. [online]. 2007, vol. 53, n.6, pp. 530-534. Disponível em: $<$ http://www.scielo.br/scielo.php?script=sci_arttext\&pid=S010442302007000600022\&lng=pt\&nrm=iso>. Acessado em: 10 dez. 2009.

NORONHA, Vânia et al . Papilomavírus humano associado a lesões de cérvice uterina. Rev. Soc. Bras. Med. Trop., Uberaba, v. 32, n. 3, jun. 1999. Disponível em: s http://www.scielo.br/scielo.php?script=sci_arttext\&pid=S0037-86821999000300003\&lng= pt\&nrm=iso >. Acessado em: 10 dez. 2009.

PINTO, ÁLVARO P.; TULIO, SIUMARA e CRUZ, OLÍVIA RUSSO. Co-fatores do HPV na oncogênese cervical. Rev. Assoc. Med. Bras. [online]. Disponível em:

$\leq$ http://www.scielo.br/scielo.php?script=sci_arttext\&pid=S0104-

42302002000100036\&lng=pt\&nrm=iso>. Acessado em: $10 \mathrm{dez} .2009$.

RABELO-SANTOS, SH et al . Human papillomavirus prevalence among women with cervical intraepithelial neoplasia III and invasive cervical cancer from Goiânia, Brazil. Mem. Inst. Oswaldo Cruz, Rio de Janeiro, v. 98, n. 2, mar. 2003. Disponível em: $<$ http://www.scielo.br/scielo.php?script=sci_arttext\&pid=S007402762003000200003\&lng=pt \&nrm=iso > . Acessado em: 10 dez. 2009. 
RAMA, Cristina Helena et al . Prevalência do HPV em mulheres rastreadas para o câncer cervical. Rev. Saúde Pública, São Paulo, v. 42, n. 1, fev. 2008. Disponível em: $<$ http://www.scielo.br/scielo.php?script=sci_arttext\&pid=S0034-

89102008000100016\&lng=pt\&nrm=iso>. Acessado em: 12 dez. 2009.

ROSA, Maria Inês da et al . Papilomavírus humano e neoplasia cervical. Cad. Saúde Pública, Rio de Janeiro, v. 25, n. 5, maio 2009. Disponível em: $\leq$ http://www.scielo.br/scielo.php?script=sci_arttext\&pid=S0102-

311X2009000500002\&lng=pt\&nrm=iso $>$. Acessado em: 18 jan. 2010.

SILVA, Terezinha Tenório da et al. Identificação de tipos de papilomavírus e de outros fatores de risco para neoplasia intra-epitelial cervical. Rev. Bras. Ginecol. Obstet. 2006, vol.28, n.5, pp.285-291. Disponível em:

<http://www.scielo.br/scielo.php?script=sci_arttext\&pid=S0100-

72032006000500004\&lng=pt\&nrm=iso >. Acessado em: 10 dez. 2009.

SMELTZER, Suzane C; BARE, Brenda G. Tratado de Enfermagem Médico-cirúrgica. Rio de Janeiro: Guanabara Koogan, 2005, vol. 2, 10ª ed. 2419 pág.

TULIO, Siumara; PEREIRA, Luciane A.; NEVES, Fabiane B. e PINTO, Álvaro Piazzetta. Relação entre a carga viral de HPV oncogênico determinada pelo método de captura híbrida e o diagnóstico citológico de lesões de alto grau. J. Bras. Patol. Med. Lab. [online]. 2007, vol. 43, n.1, pp. 31-35. Disponível em:

$<$ http://www.scielo.br/scielo.php?script=sci_arttext\&pid=S1676-

24442007000100007\&lng=pt\&nrm=iso>. Acessado em: 18 dez. 2009. 